\title{
What a Ride - Change @ the Presbyterian Research Centre by Anne Jackman
}

\author{
The Archive \& Library for the \\ Presbyterian Church of Aotearoa NZ
}




\section{Our role}

- Preserving the history of the life of the Presbyterian Church in NZ

- Supporting the Knox Centre for Ministry \& Leadership staff \& students

- Providing resources for ministers, and those working in the church

- Giving access to all members of the church, and others with an interest in theology

\section{Knox College site, Dunedin}

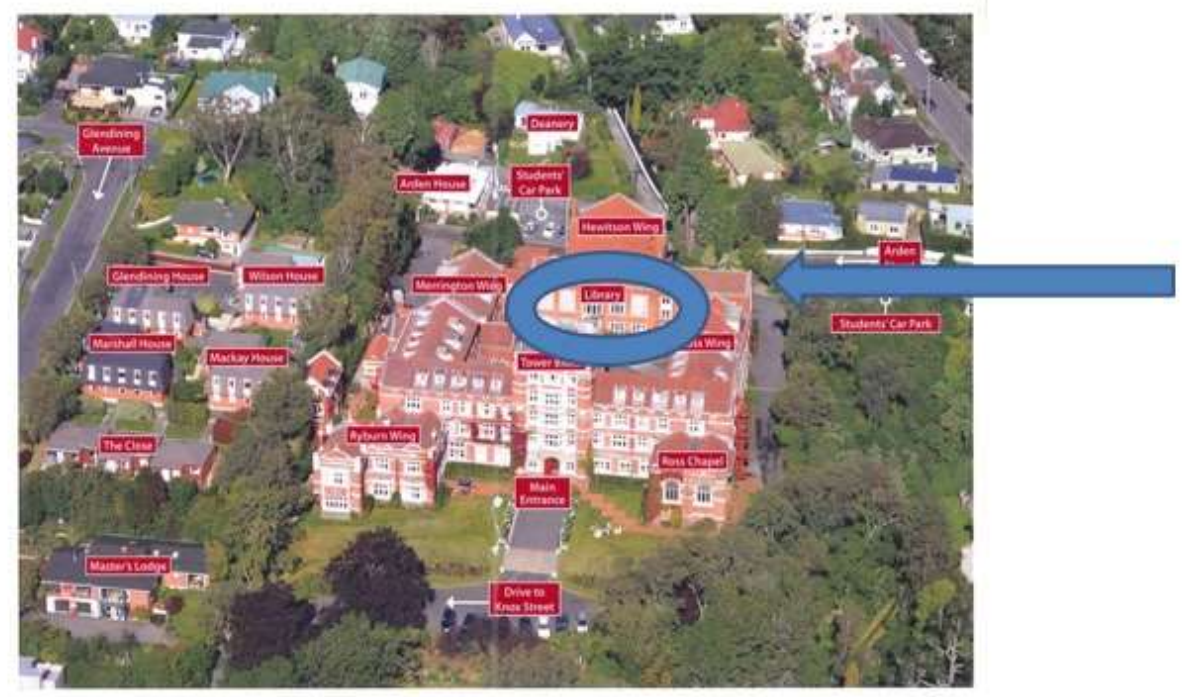




\section{We also}

- Support the academic programs of the Universities in NZ, particularly the University of Otago

- Work within the heritage sector (GLAM) to ensure NZ's heritage resources are protected

- Provide access to groups such as genealogists, independent historians

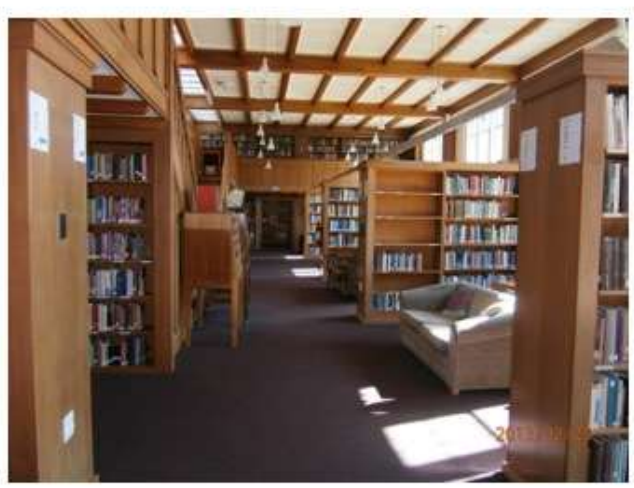

Hewitson Library

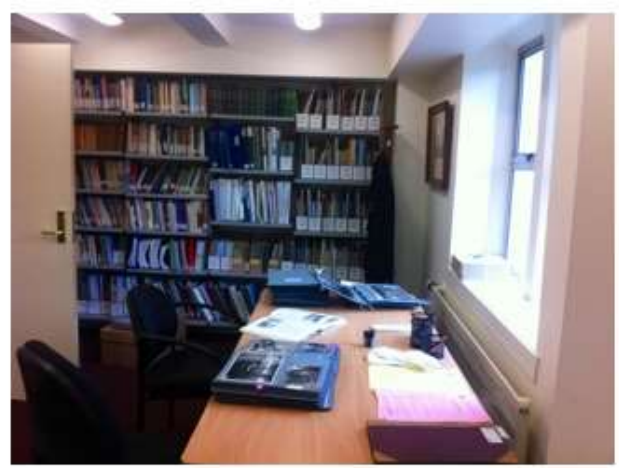




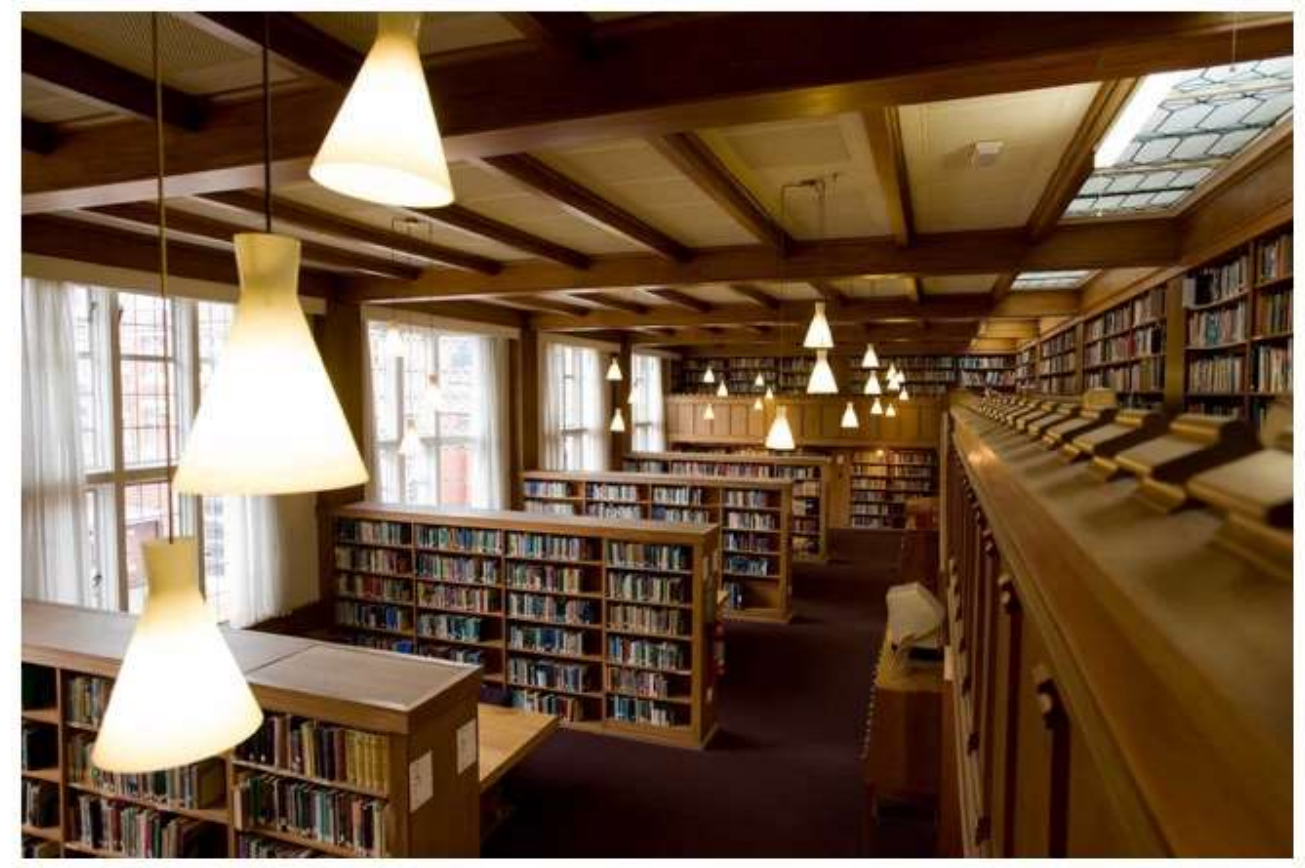

\section{Strategies}

- Work to a plan, be clear about priorities

- Bring the staff along with you

- Target key members of stakeholder groups

- Use accessible technology, often at little or no cost

- Be visible and noisy

- Show increased value to funders

- Improve online presence

- Be open to opportunities 


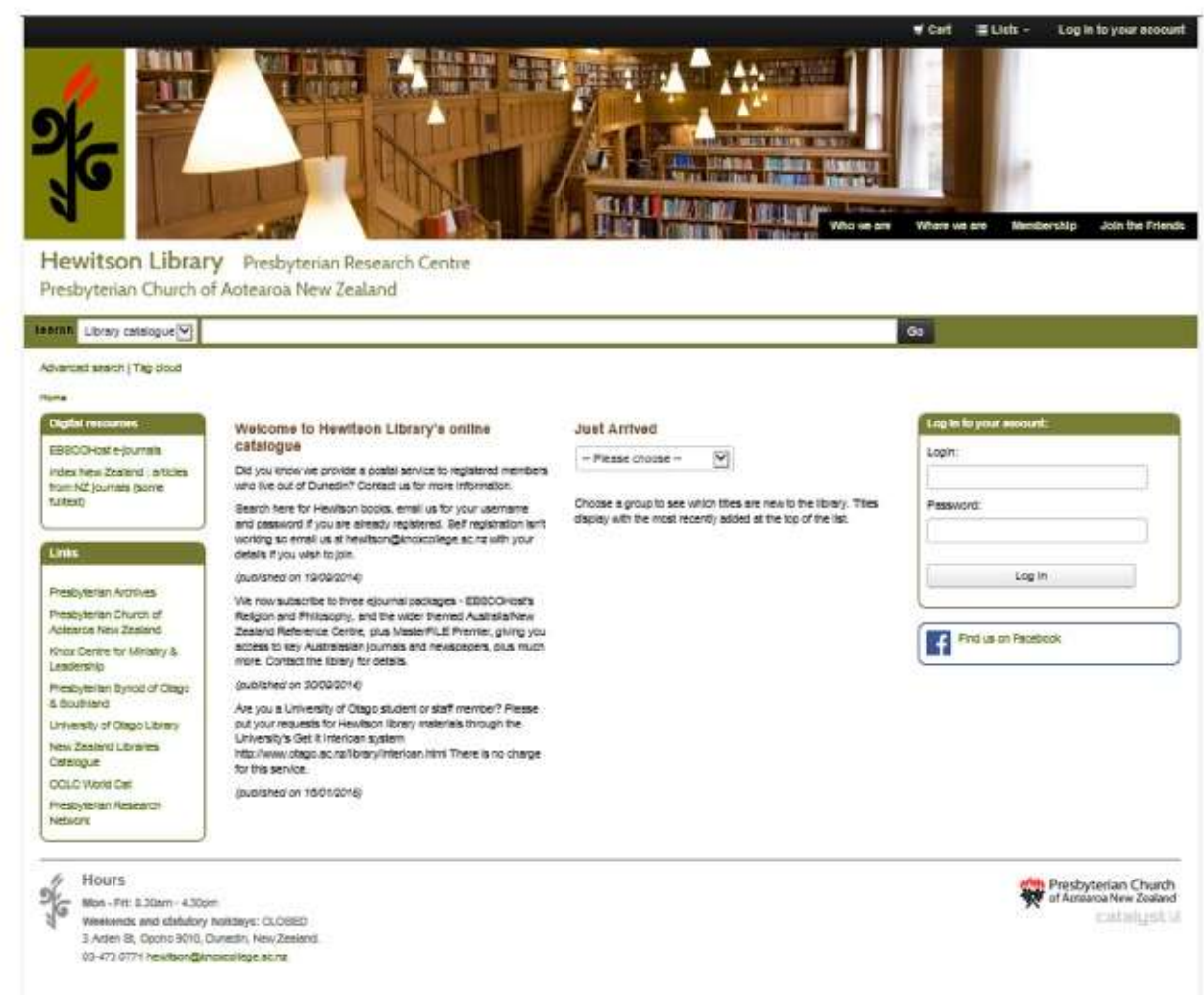

\section{Successes}

- Better balance of use by key groups

- Supportive manager

- Some wins in funding

- Staff own the processes

- Some way towards better online presence

- Positive feedback and appreciation

- Collaborations with external organisations

- Capacity to deal with born digital 


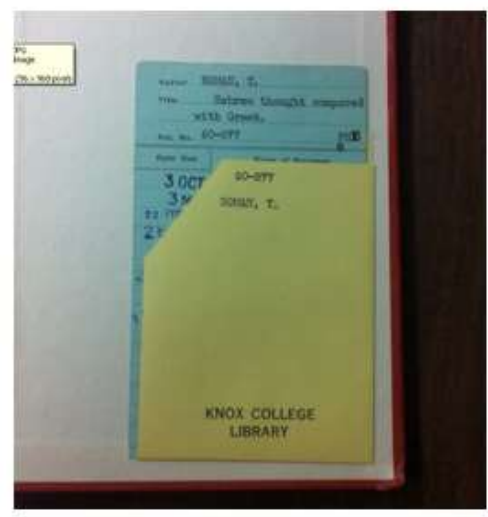

To the benefits of an automated one

\section{From a manual system}

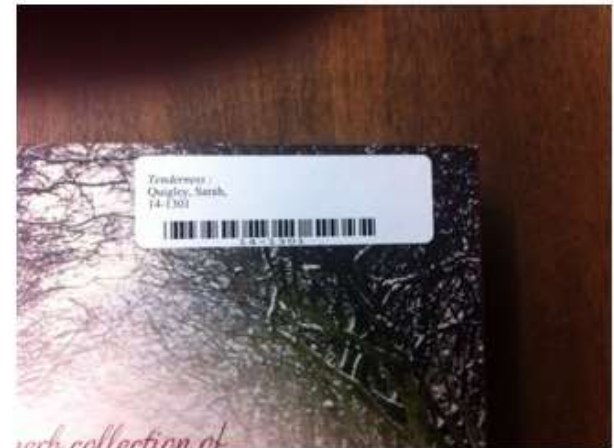

\section{Thank you}

\section{anne.jackman@knoxcollege.ac.nz}




\section{Some photographs from our collection for question time ...}

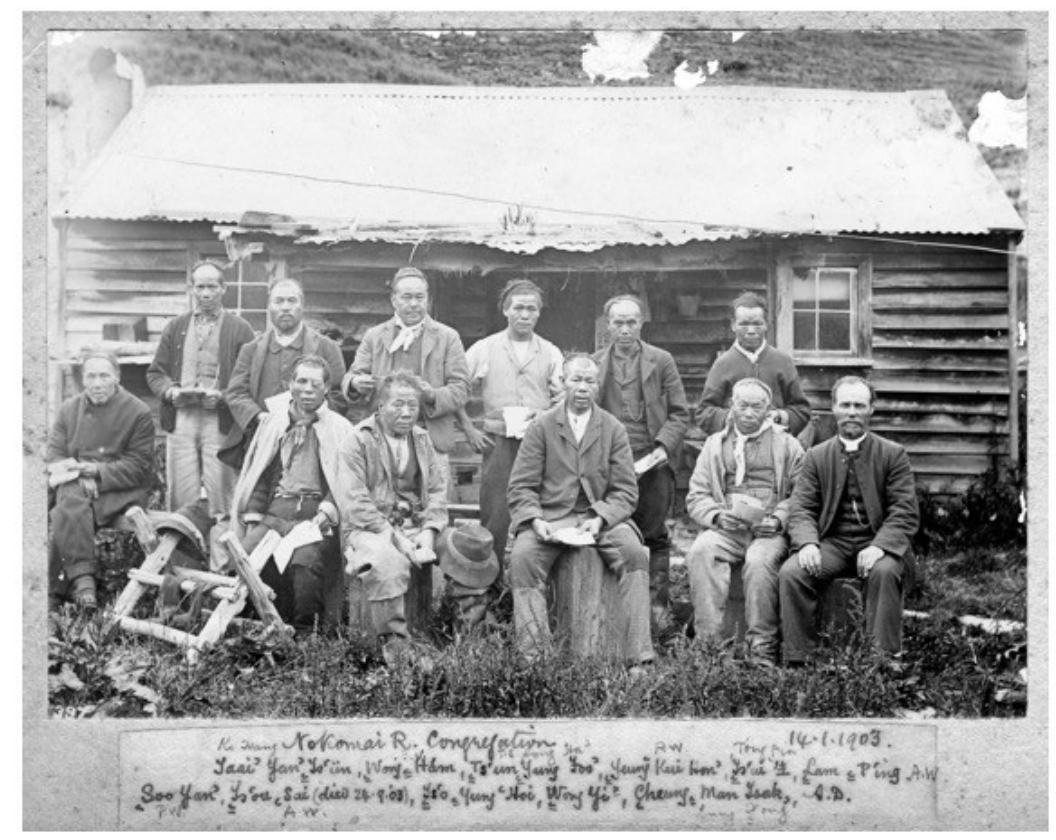

Alexander Don Album: Nokomai River Congregation 14.1.1903 [PCANZ Archives A-S12-49.8 ] 


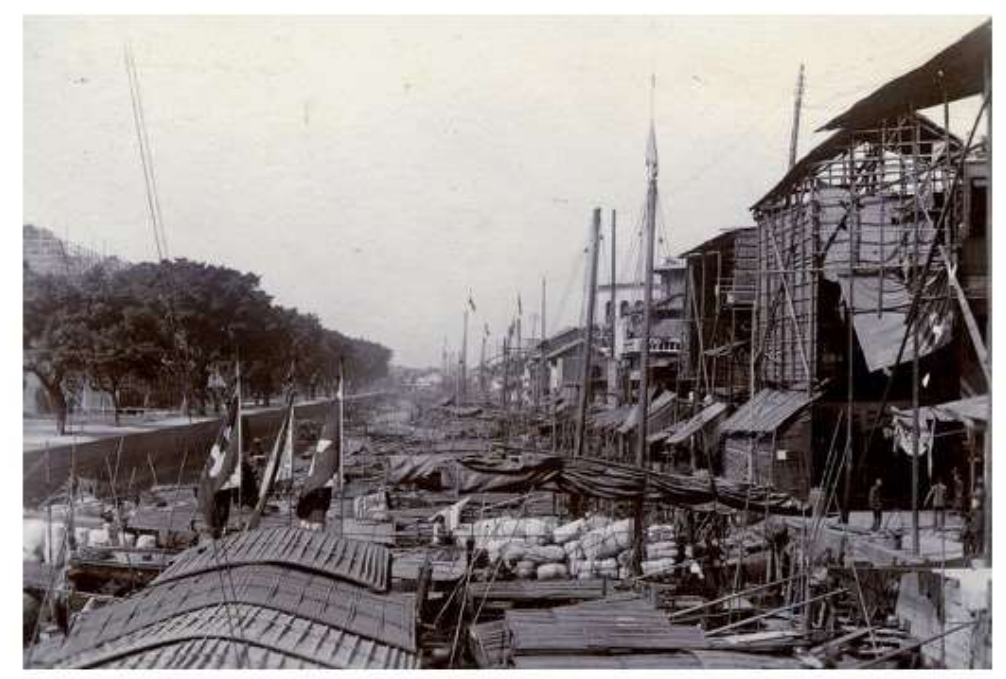

Canton - Canal at Shameen

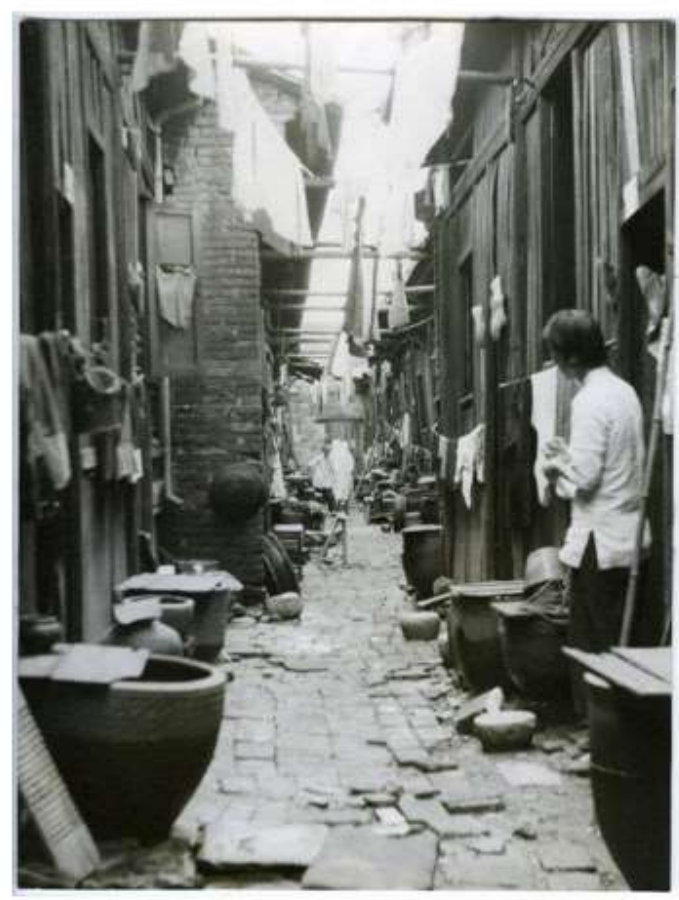

Canton-street scene 


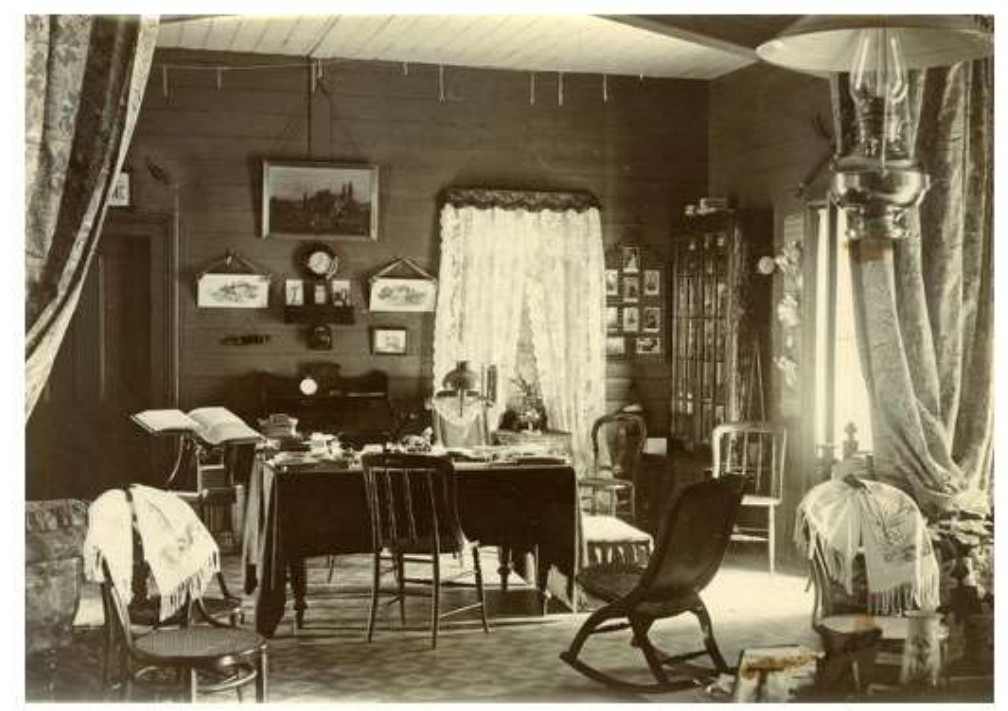

Dr Annand's study, Mission House, Tangoa, c1899 [PCANZ Archives A-517-79.4-6]

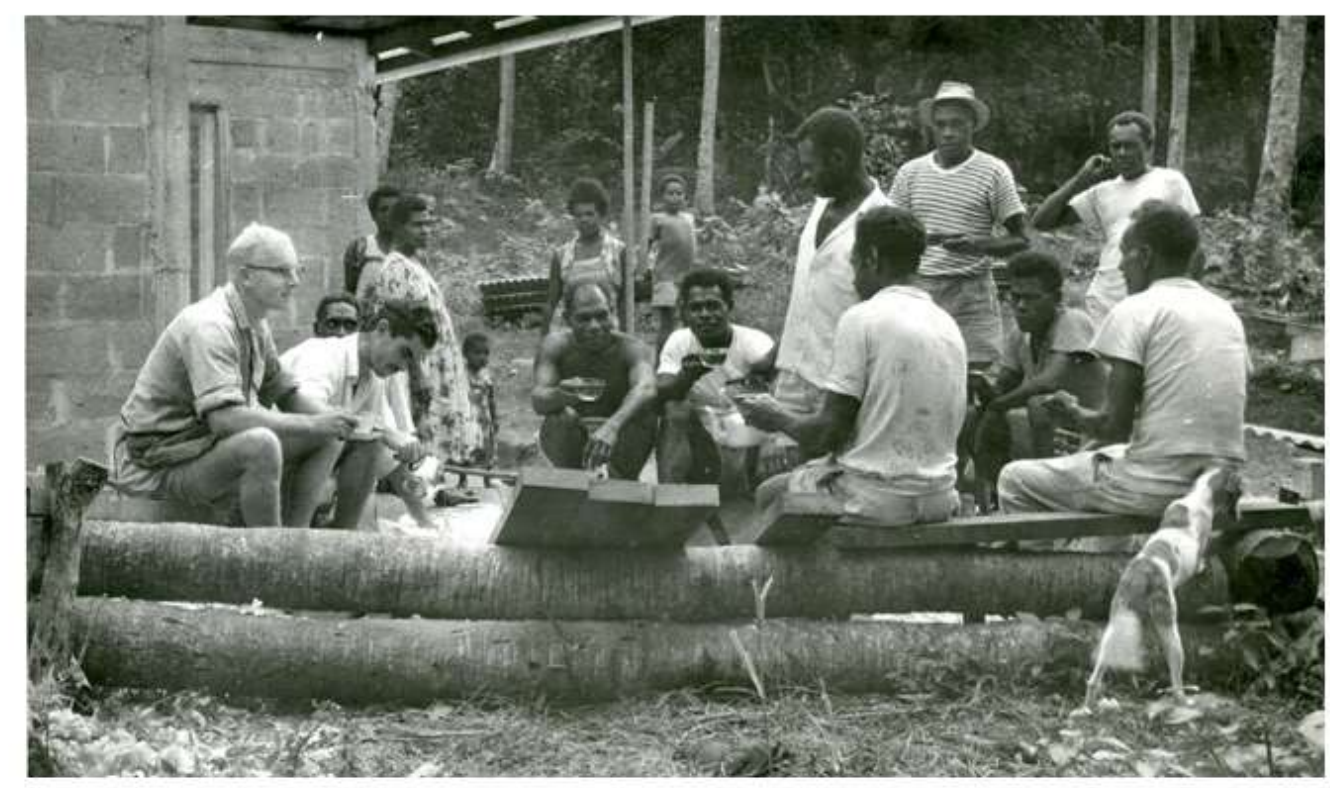

Volunteer party to New Hebrides - fence building 


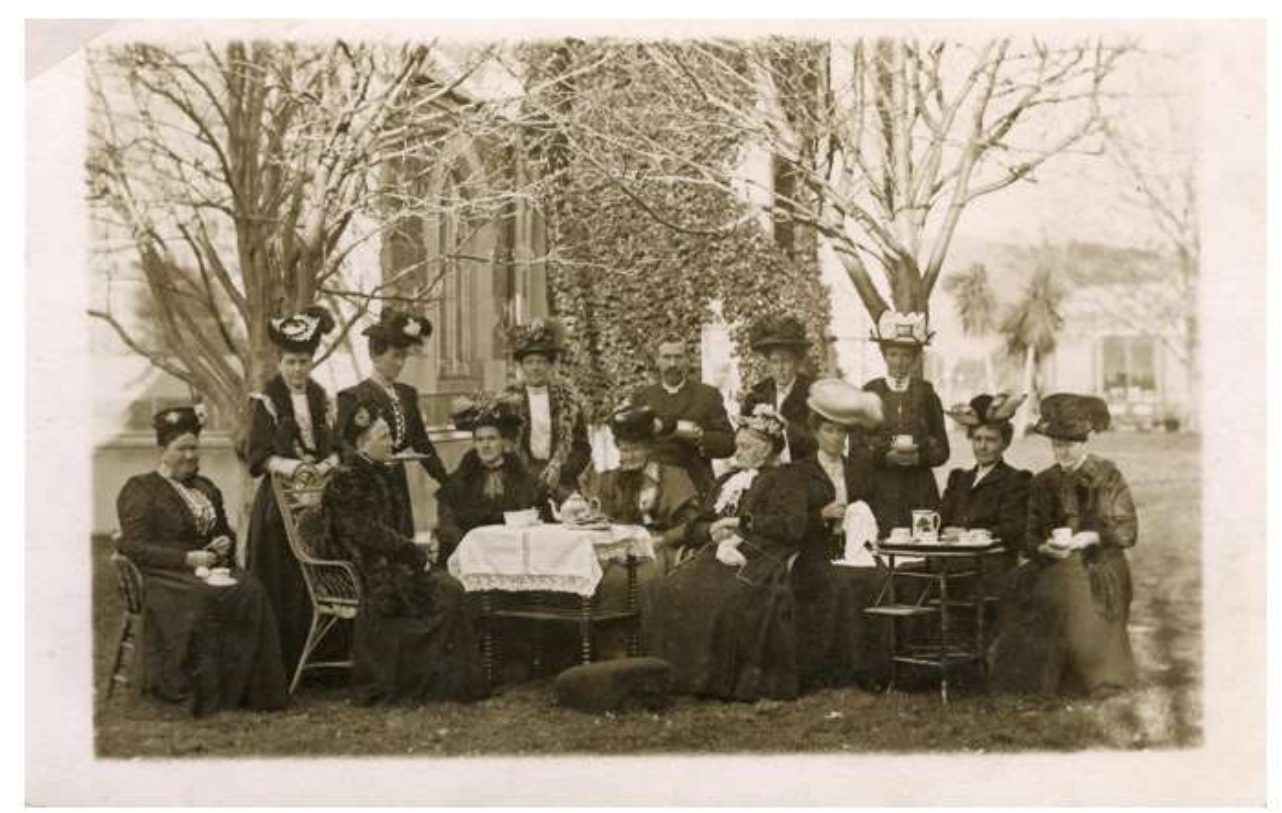

Postcard of a 'tea party' held by the Tokomairiro Presbyterian Women's Missionary Union (PWMU)

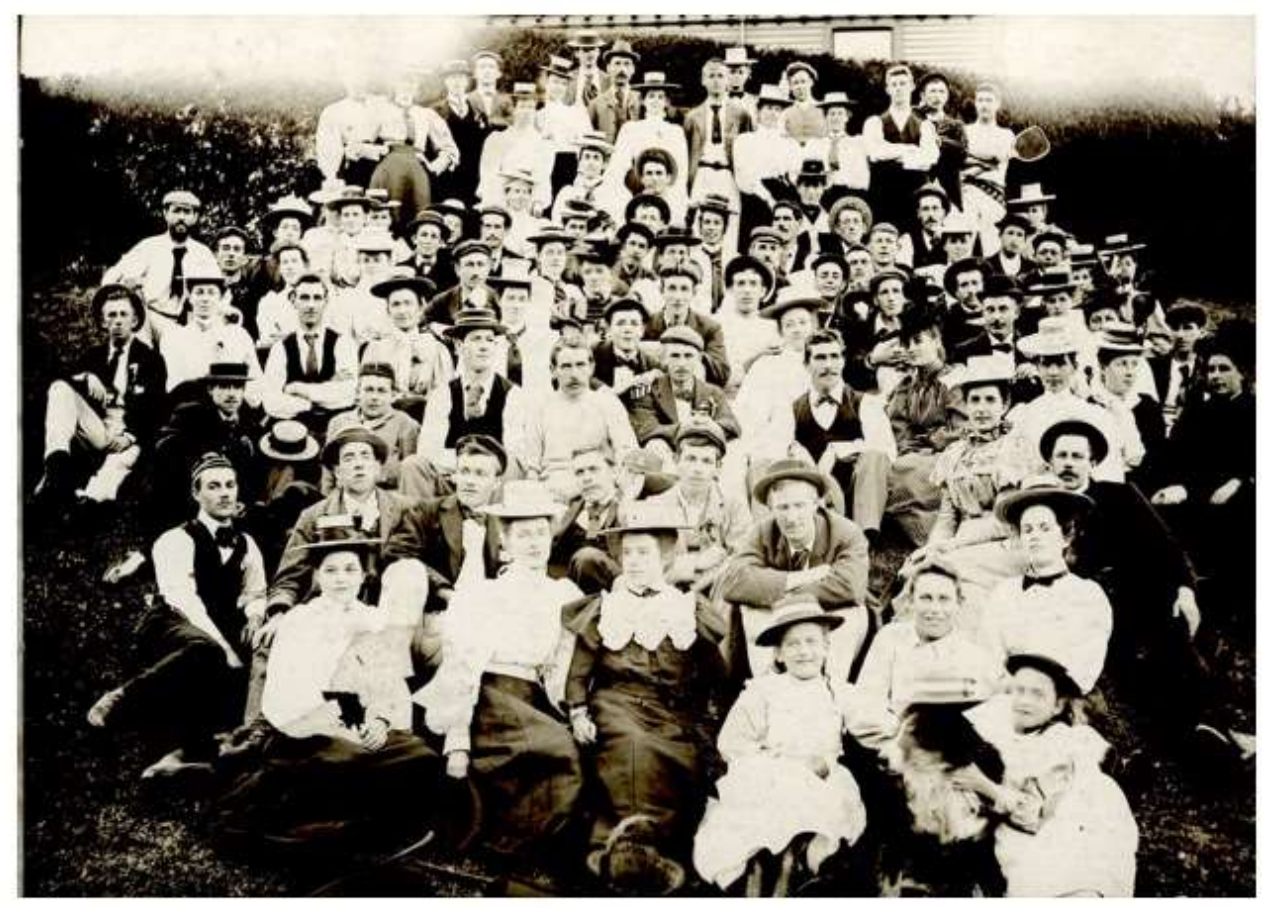

St Johns (Wellington) and St Paul's (Christchurch) Bible Classes, 1898 [PCANZ Archives P-S19-2] 


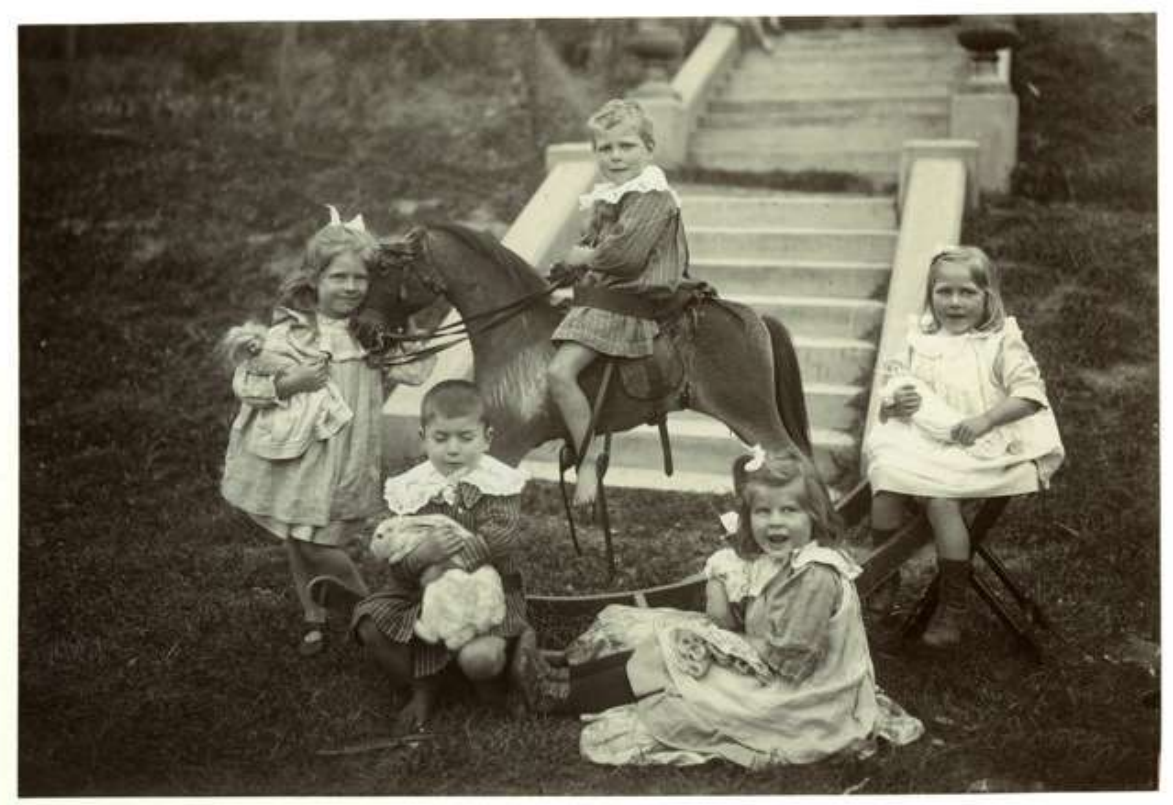

Children from a PSSA Home. n.d. [PCANZ Archives A-S18-76-3001]

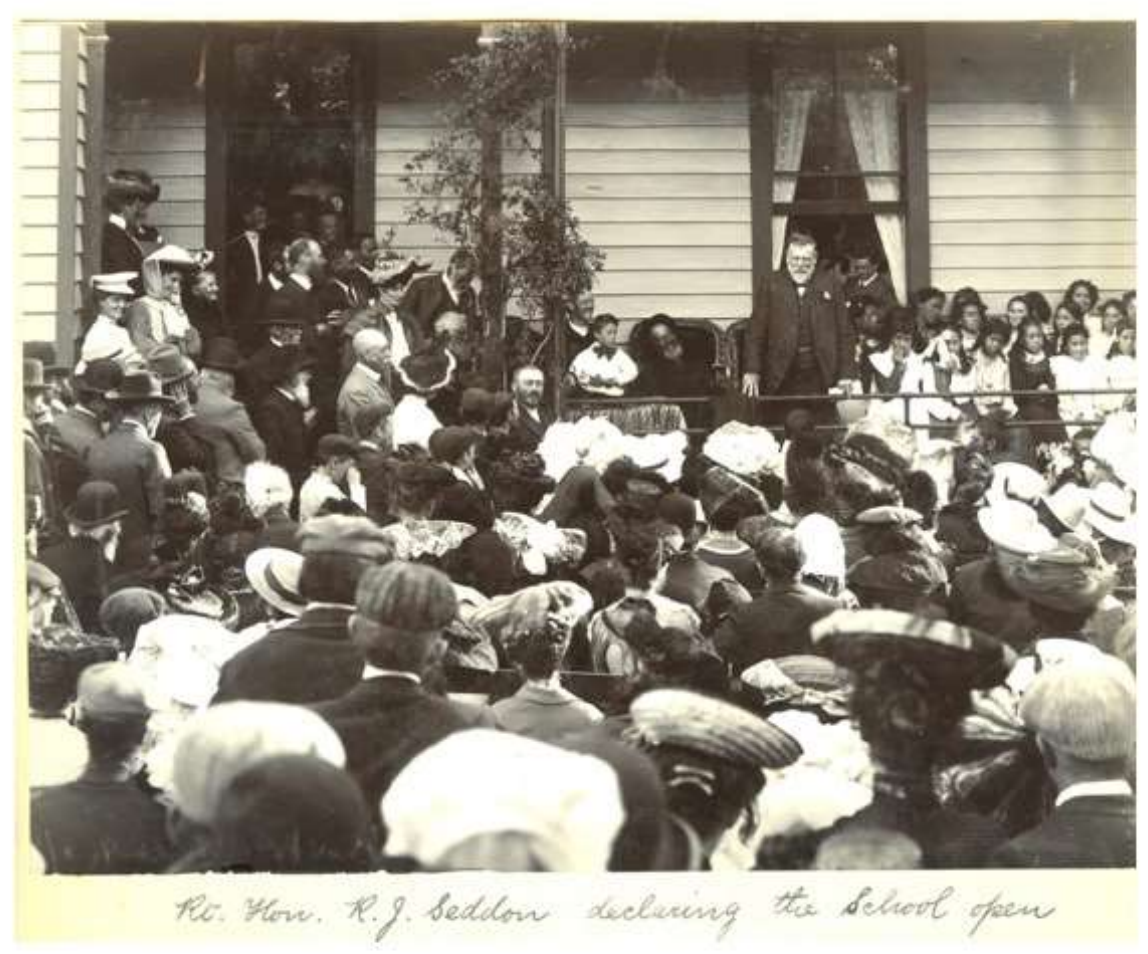

Rt Hon Seddon opening Turakina Maori Girls' School, 13 April 1905 [PCANZ Archives A-S2-8.47-114] 


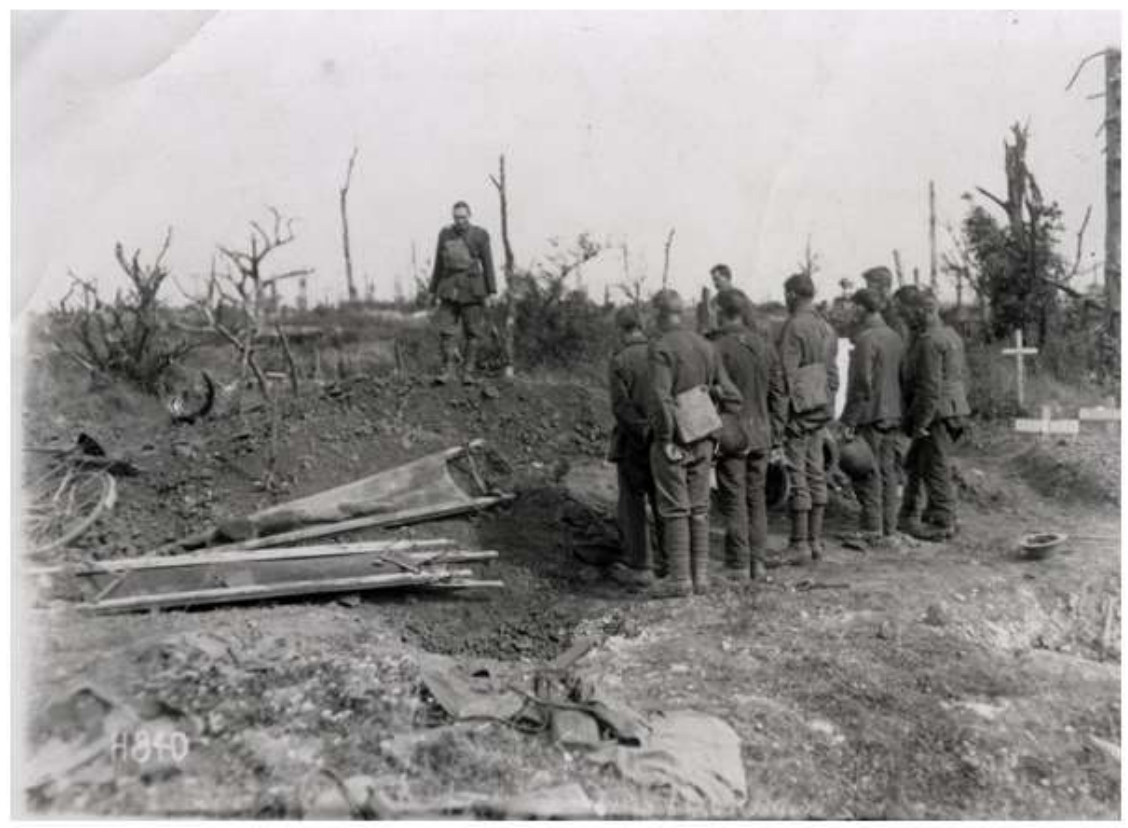

Rev. D.C. Herron conducting military funeral at Gommecourt, France, 1918 [PCANZ Archives P-L22-22(A)]

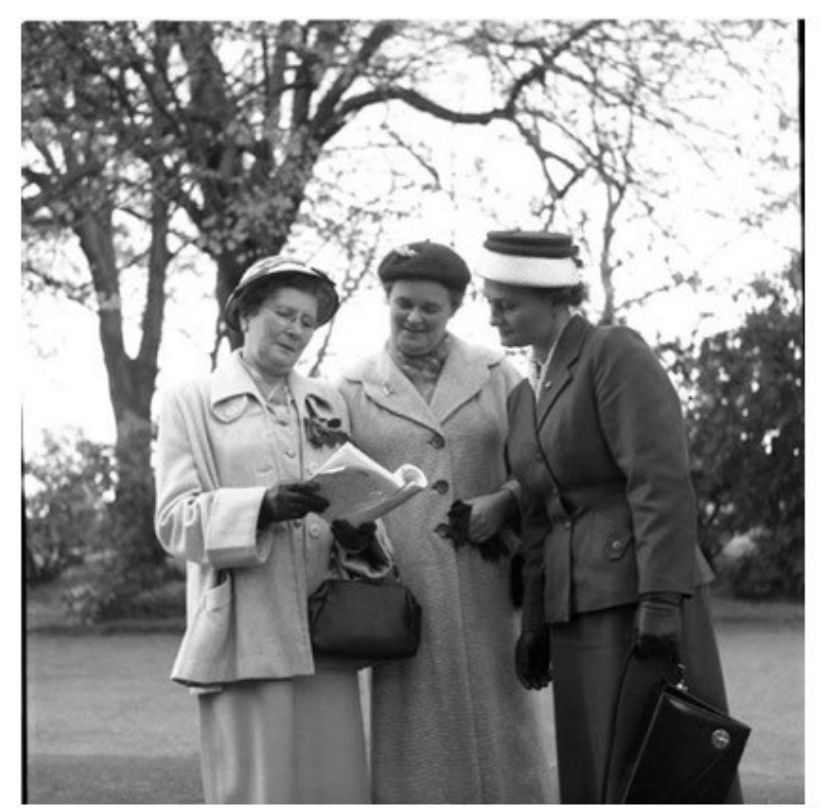

The women attending their first Assembly as Elders are: (I-r) Mrs W.H.O Johnston, Tokomaru Bay; Sister Margaret Hewson, Wellington, Mrs. E.M. Webb, Papatoetoe. 


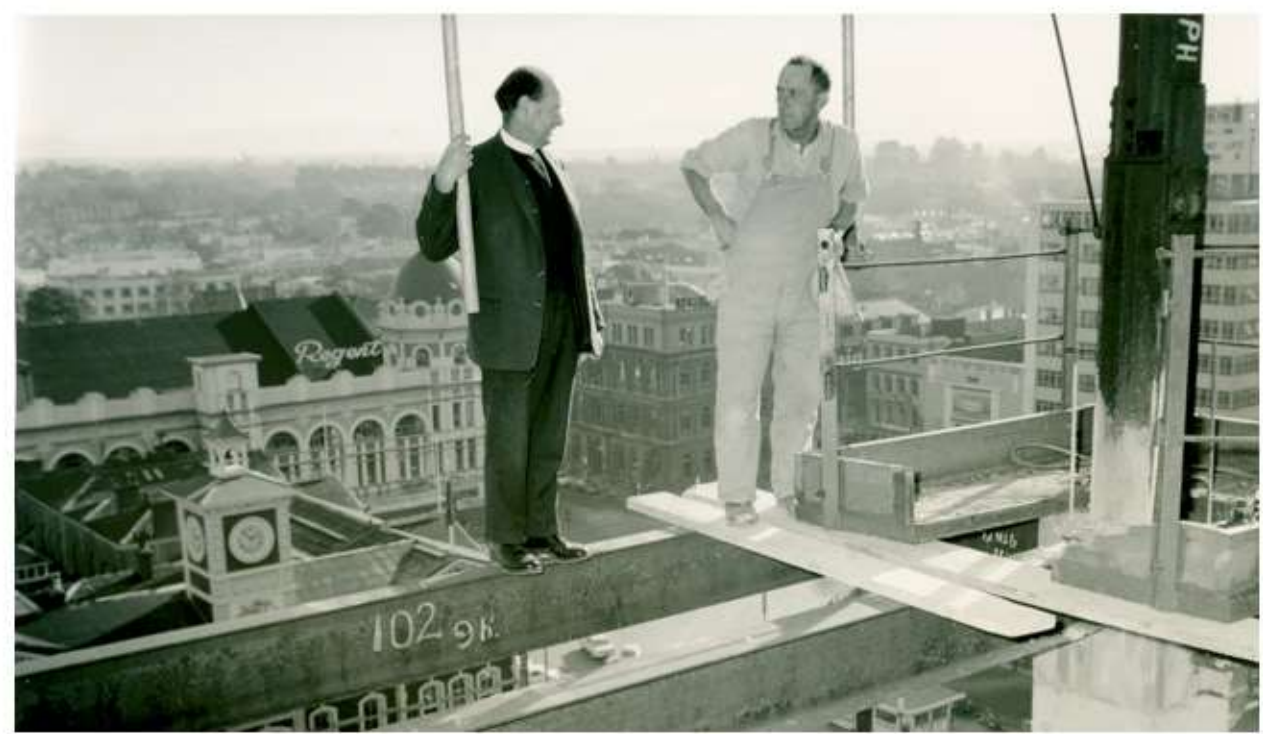

Rev K A Hadfield standing on a steel girder overlooking Cathedral Square, Christchurch, during the construction of the Bank of New Zealand building, 1966 [PCANZ Archives, P-A120.25-51] 